\title{
IMPLEMENTASI
}

\section{MODEL PEMBELAJARAN KEWIRAUSAHAAN BERBASIS KOMPETENSI DAN PENGALAMAN UNTUK MENCIPTAKAN WIRAUSAHA BARU \\ PADA SISWA SMK YOGYAKARTA}

\author{
Hari Rachmadi \\ Dosen Sekolah Tinggi Pariwisata Ampta Yogyakarta \\ e-mail harri.rachmadi@yahoo.com
}

\begin{abstract}
The strength of character to be entrepreneurs, the strength of the motivation to start and own a business, entrepreneurial perception, the seriousness of the effort to seek opportunities and take advantage of business opportunities and perseverance run Synchronize employment policies, business and academia showed peranstrategis in building an entrepreneurial culture both in shaping new entrepreneurs, as well as for survival both businesses large and small to create the nation's economic added value. In addition, the study empirismenunjukkan that entrepreneurship program has a positive effect on the development of entrepreneurial attributes of individual, self-reliance, raise awareness of entrepreneurship a career option and instill a positive attitude towards entrepreneurship.

Opportunities offered competency-based model of entrepreneurial learning and experience (competence base and experience entrepreneursship learning - CBE2L) are implemented systematically, challenges and implications for policy makers, employers and types usahadibahas in relation to relevant theoretical perspectives.

Key implications CBE2L models. is to encourage learning program with policy and institutional commitment of resources, teachers who have the knowledge and experience of entrepreneurship and disseminate issues of education dalammemperkuat involvement entrepreneurial culture among students.
\end{abstract}

Keywords: Burning Motivation, Courage and Perseverance entrepreneurs start businesses.

\section{PENDAHULUAN}

Dari tahun ke tahun bangsa ini terus bergulat dengan masalah pengangguran, satu diantara penyebabnya adalah tingkat pertumbuhan lapangan kerja yang rendah, dan ini akan terus memperpanjang barisan pengangguran terdidik. Sebagai gambaran, data Kemndiknas yang dicatat oleh Asri Tadda (2010) menunjukkan bahwa :
1. Minat lulusan lembaga pendidikan untuk berwirausaha sangat rendah, yaitu 22,63 persen lulusan SLTA, 6,14 persen lulusan perguruan tinggi, 32,46 persen berpendidikan dasar (SD dan SMP) justru memiliki kemandirian untuk berusaha sendiri.

2. Para pemuda yang berpendidikan 61,87 persen SLTA dan 83,2 persen sarjana 
memilih menjadi pekerja atau karyawan dibanding menjadi wirausaha.

Angka tersebut menunjukkan bahwa semakin tinggi tingkat pendidikan seseorang, semakin rendah kemandirian dan motivasi untuk menjadi wirausaha.karena itu program pembelajaran kewirausahaan merupakan salah satu strategi penting untuk memotong kecenderungan sebagai job seeker menjadi job creator di waktu-waktu mendatang. Ini menjadi alasan utama perlunya membangun motivasi dan semangat kewirausahaan pada siswa agar mereka memiliki rasa percaya diri, selalu ingin maju, mampu melihat peluang dan memanfaat-kannya, selalu ingin berprestasi, kreatif, inovatif, mandiri, pantang menyerah dan berani mengambil resiko (I Gusti Putu Darya, 2012)

Sampai saat belum ada yang berani dan bisa membantah bahwa untuk menjadi bangsa yang maju dan sejahtera, dibutuhkan wirausaha minimal di kisaran $2 \%$ dari jumlah penduduk. Indonesia baru memiliki 1,56 persen atau sekitar 3.707.184wirausaha dari jumlah populasi penduduk Indonesia. Menyadari pentingnya peran wirausahawan dalam membangun perekonomian, pemerintah mimpi dan berambisi untuk mencapai persentase wirausahawan Indonesia yang menyamai Amerika Serikat (AS) sebesar 11,5\%, China dan Jepang denganjumlah wirausahanya $10 \%$, Singapura dan Malaysia yang masing-masing 7,2\% dan 5\%. Idealnya untuk mencapai kemajuan dan kesehjateraan suatu bangsa, dibutuhkan wirausahawan minimal sebanyak 2 persen dari populasi penduduk (Pidato Menteri Koordinator Bidang Perekonomian Hatta Rajasa pada acara Wisuda Sarjana dan Pascasarjana Universitas Ahmad Dahlan Yogyakarta, Sabtu, 6/7/2013).

Disisi lain, Menteri Koperasi dan UKM menunjukan jumlah wirausahawan di Indonesia baru mencapai 1,56 persen dari total penduduk 237,64, juta orang (Rakyat Merdeka Online, Rabu, 04 September
2013). Sementara itu paradigma SMK sudah sejak lama dikenal sebagai sekolah yang diperisapkan untuk menghasilkan siswa yang handal didunia kerja, faktanya masih cenderung menjadi job seeker dari pada sebagai job creator.

Paradigm ini masih memerlukan perjuangan panjang diantaranya melalui perbaikan kurikulum, penambahan imprastruktur pendidikan, pengadaan buku, perbaikan kualitas guru dan tidak kalah pentingnya adalah perbaikan model pembelajaran.

Dalam konteks penelitian ini model yang dimaksud adalah model pembelajaran kewirausahaan berbasis kompetensi dan pengalaman (competence base and experience entrepreneurship learning$C B E 2 L$ ) dalam pembentukan wirausaha baru. Tujuan utamanya adalah untuk mendorong para siswa mengejar impian untuk mengorganisir potensi dan mengoperasikan usaha, menciptakan lapangan kerja dan menciptakan pertumbuhan ekonomi.

Inti Model $C B E 2 L$ bagaimana mengembangkan usaha. Semua orang tahu bahwa siswa adalah kaum intelektual muda terpilih untuk mengembangbiakkan kreativitas, pertukaran ide, cara melihat, merespon dan mempelajari hal-hal baru serta energik.

1. Apakah model CBE2L dapat mengembangkan dan mengintegrasikan kekuatan karakter menjadi wirausaha, kekuatan motivasi untuk memulai dan memiliki usaha, persepsi wiausaha, keseriusan upaya mencari kesempatan dan memanfaatkan peluang dan ketekunan menjalankan usaha dan kemampuan membuat rencana bisnis menjadi perilaku start up bisnis (wirausaha baru) yang mandiri?

2. Apakah model CBE2Ldapat mengintegrasikan pembelajaran materi manajemen bisnis, magang 
kewirausahaan, kunjungan dan konsultasi bisnis untuk membangun kemampuan membuat rencana bisnis menjadi perilaku start up bisnis (wirausaha baru) yang mandiri ?

\section{LANDASAN TEORI}

\section{Road Map Penelitian}

Wirausahawan pada level pendidikan menengah yang dapat secara langsung dengan masalah kewirausaan adalah SMK yang terus menerus dikembangkan agar para siswa memiliki keinginan dan kemampuan berwirausaha.

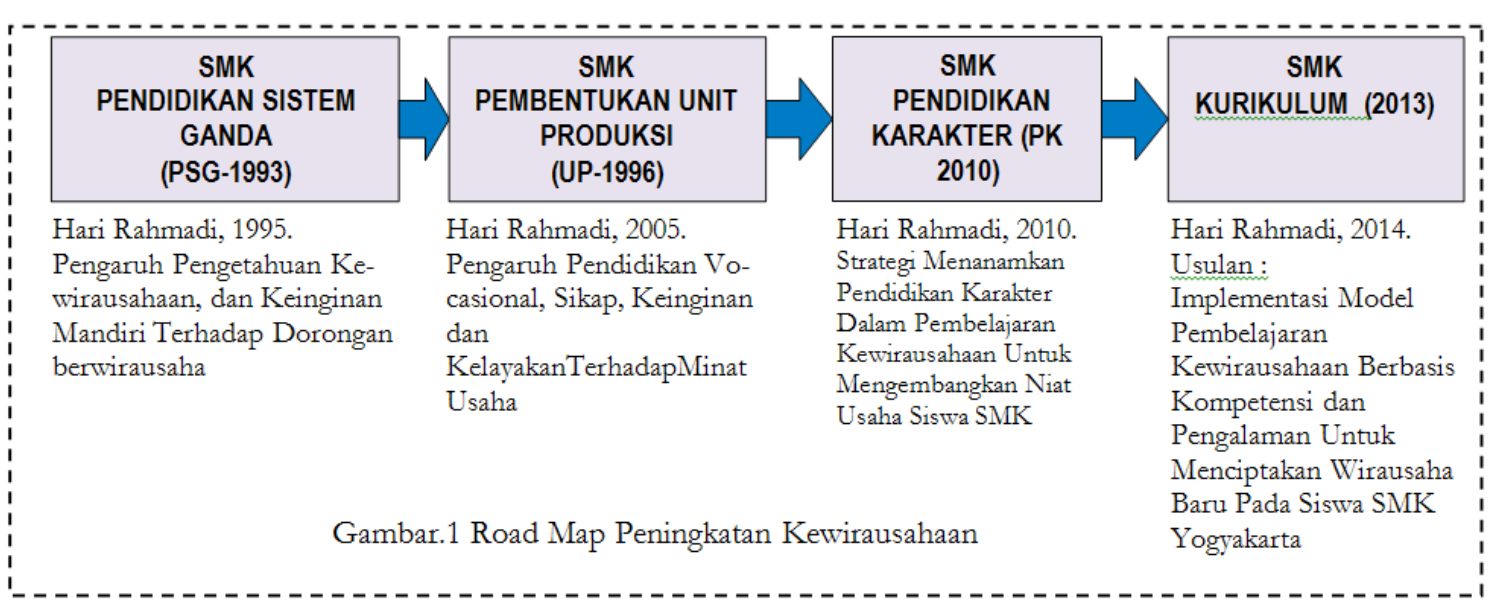

Dari road map di atas nampak relevansi alur pemikiran dan kegiatan penelitian yang saat ini diusulkan merupakan kelanjutan dari penelitian yang sudah pernah dilakukan oleh peneliti sebelumnya.

\section{Power Kewirausahaan}

Pembelajaran kewirausahaan dengan model $C B E 2 L$ memiliki korelasi tinggi dengan keyakinan individu untuk terlibat dalam usaha, infrastruktur $C B E 2 L$ seperti sumberdaya kewirausahaan, fasilitas pendukung kegiatan, akses pasar, relasi bisnis dan teknologi memainkan peran penting dalam membentuk budaya kewirausahaan dan dalam mendorong setiap siswa untuk terlibat dalam kegiatan kewirausahaan.

Menurut Anderson dan Jack (2008), 99\% dari UKM mampu menciptakan ratusan ribu pekerjaan, mampu menciptakan kontribusi ekonomi dan sosial, mereka menjadi mesin pertumbuhan perekonomian sebuah negara.

\section{Kewirausahaan}

Kewirausahaan didefinisikan sebagai katalitas inovasi untuk menciptakan perubahan radikal, membawa inovasi ke pasar, menciptakan nilaitambah bagi individu dan masyarakat, meningkatkan kesempatan sosial dan komersial (Fadzean, Loughlin, dan Shaw, 2005). Model CBE2Lberfokus pada upaya mempromosikan kewirausahaan; membina kemampuan kewirausahaan individu; mengubah ide menjadi tindakan yang didukung oleh tingkat kreativitas, inovasi dan keberanian mengambil resiko, kemampuan untuk merencanakan dan mengelola semua potensi dalam rangka mencapai tujuan, lebih mampu menangkap peluang, membangun kegiatan komersial dan sosial.

\section{Inovator Bisnis}

Pengetahuan yang berkaitan denganindustri, produk, teknik atau proses. Keterampilan, mencakup keterampilan network, keterampilan manajemen (produksi, marketing, keuangan dan SDM), keterampilan komunikasi untuk 
mengembangkan jaringan sosial yang luas, dan keterampilan dalam pengambilan keputusan (Gibbs, 2002; Cope, 2005). Sikap berkaitan dengan keberanian memulai bisnis, kekuatan psikososial, kegigihan dan berorientasi pada perubahan serta lingkungan budaya setempat dalam mempengaruhi perilaku kewirausahaan (Marvel dan Lumpkin, 2007).Sementra itu Belousova, Gailly, dan Basso, (2010) menjelaskan bahwa perilaku kewirausahaan berkaitan dengan kebutuhan untuk berhasil sangat tinggi, memiliki daya suai dan level energi yang tinggi, gigih dan fokus melakukan terbaik untuk kesuksesan bisnis, dan memiliki keberanian untuk mengambil risiko (risk taking tendency). Oleh karena itu Model CBE2Ldirancang fokus pada upaya :

1. Menyampaikan pengetahuan yang berguna bagi pengembangan budaya kewirausahaan;

2. Menyampaikan metode atau alat untuk menganalisis dan memindai lingkungan bisnis dan mengembangkan rencana bisnis;

3. Mengembangkan keterampilan, drive dan potensi kewirausahaan;

4. Merangsang berpikir kreatif, mendorong semangat untuk mengejar dan mendukung perilaku kewirausahaan;

5. Mengembangkan sikap individu yang positif, mampu mengatasi dan mengubah hambatan menjadi peluang; dan

6. Mendorong, mendukung start-up bisnis dan pengembangan usaha.

\section{Pengembangan Kerjsasama}

Mengembangkan dan memanfaatkan pembelajaran kewirausahaan harus merupakan bentuk pendekatan kolaboratif untuk membudayakan kewirausahaan berbasis pengalaman dan tindakan. Cara ini memungkinkan transfer pengalaman, pengetahuan pengusaha dalam meningkatkan dan mengembangkan siswa menjadi lebih giat(Rae dan Carswell, 2000; Watkins, 2009). Model kerjasama dengan industri mitra untuk mempromosikan kewirausahaan difokuskan pada pembelajaran berorientasi tindakan yang ditawarkan kepadasiswa. Pembelajaran ini dapat dimaksimalkan dengan kegiatan perusahaan, terus-menerus dan pengulangan (Cope, 2005) secara intensif dan memotivasi pengalaman, merefleksi dan konseptualisasi proses pembelajaran (Gibb, 2002). Selain itu, dengan memasukan pengusaha dalam proses fasilitasi, penilaian, dan mentoring kegiatan magangpara siswa, bertukar pengalaman dan pengetahuan selama proses pembelajaran, pemagangan, kunjungan dan konsultasi bisnis serta lokakarya memungkinkan siswa untuk memulai usaha dengan penuh semangat

\section{Model CBE2L}

Komitmen pembelajaran kewirausahan adalah proses mempromosikan pemikiran kreatif, lintas-fungsional (multi disiplin), pendekatan integratif dan holistik (Tan and $\mathrm{Ng}, 2006$ ), untuk membangkitkan energi dan motivasi entrepreneurship siswa, mendampingi siswa yang berkreatif, menghasilkan entrepreneur baru dari kalangan siswa, mendampingi siswa untuk membuat badan usaha, termasuk merintis/ membuatn etworking antara IbK dengan penyandangdana CSR. Menurut Ali Hasan dan Budi Hermawan (2014), upaya membudayakan kewirausahaan dikalangan siswa dikemas melalui sebuah siklus seperti dalam gambar 2.1 yang menggambarkan sebuah proses pembelajaran kewirausahaan melaluilima kegiatan:

1. Siswa diwajibkan mengikuti kegiatan "pembakaran" motivasi khususnya membangun kekuatan karakter menjadi wirausaha, kekuatan motivasi untuk memulai dan memiliki usaha, persepsi wiausaha, keseriusan upaya mencari kesempatan dan memanfaatkan peluang dan ketekunan 
menjalankan usaha dan kemampuan membuat rencana bisnis menjadi perilaku start up bisnis (wirausaha baru) mandiri

2. Siswa diwajibkan mengikuti konseptualisasi dan integrasi pengetahuan manajemen bisnis (organisasi, produksi, sdm, pemasaran dan operasional) secara klasikal, magang kewirausahaan, kunjungan dan konsultasi bisnis untuk membangun kemampuan membuat rencana bisnis menjadi perilaku start up bisnis (wirausaha baru) mandiri.

3. Siswa diwajibkan mengikuti kegiatan pemagangan, kunjungan (studi lapangan atau studi banding) dan konsultasi

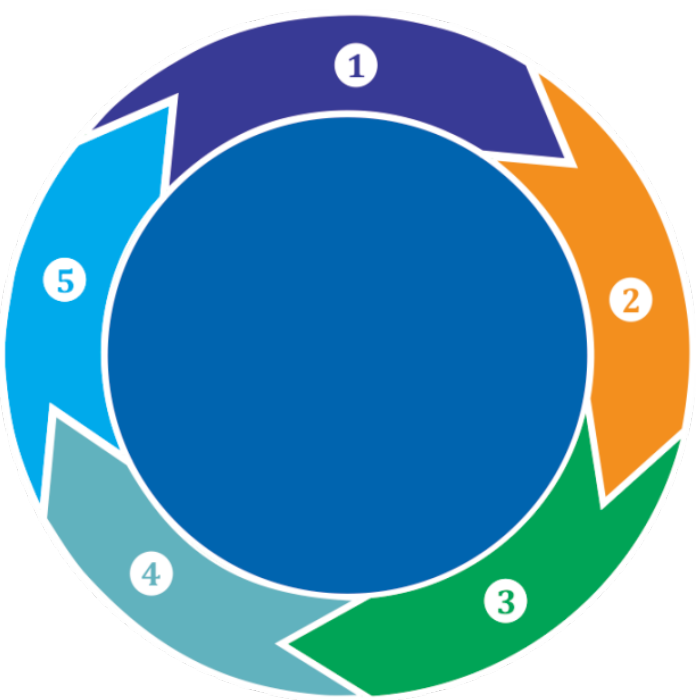

Gambar .2 Siklus CBE2L

(sharing) kewirausahaan dengan mitra industri;

4. Siswa diwajibkan untuk merefeleksikan atau mereviu pengalaman belajar kewirau-sahaan dilapangan; dan mengkristalisasikan pengetahuan dan pengalaman belajar kewirausahaan dalam sebuah rancangan bisnis; serta

5. Siswa diwajibkan untuk mempersiapkan start up bisnis dan mengikuti layanan pembimbingan untuk memastikan bahwa kegiatan usaha siswa dapat berjalan sesuai prinsip-prinsip pertumbuhan bisnis yang sehat.
Siklus pembelajaran pengalaman tindakan berlangsung dimana siswa secara individual berinteraksi dengan orangorang dan lingkungan usaha. Pembelajaran kewirausahaan berbasis komptensi dan pengalaman semacam ini akancenderung bersifat dinamis, kontekstual, intuitif, kumulatif, pengulangan dan on-going (Cope, 2005) dalam melibatkan siswa belajar berinteraksi dengan lingkungan bisnis, jaringan sosial dan pekerjaannyasendiri (Gibb, 2002). Pembelajaran kewirausahaan sebagai sesuatu yang dinamis, artinya pengetahuan untuk berwirausaha didasarkan pada akumulasi pengalaman sebelumnya yang diperoleh dari sebuah siklus pembelajaran dan interaksi mereka dengan lingkungan bisnis, jaringan sosial dan pekerjaannya sehari-hari (Minniti dan Bygrave, 2001) diyakini paling sesuai dalam upaya mendorong siswa untuk:

1. Bereksperimen dengan ide-idenya sendiri untuk melakukan start-up bisnis, sesuai disiplin akademisnyaatau keinginan siswa;

2. Merefleksikan atau merenungkan kembali pengalaman dan kemudian belajar untuk meng-up date pengetahuan bisnisnya;

3. Mencari lebih banyak pengetahuan dan pemahaman teoritis tentang ideide bisnis untuk mengembangkan bisnisnya (diversifikasi dan regulasi), dan keberaniaan mencoba ide-idenya sendiri melalui model trial and error;

4. Berupaya memperoleh dan mengumpulkan pengalaman sebanyakbanyaknya yang menyediakan siswa sebuah bank pengetahuan dan memanfaatkannya untuk pengembangan bisnisnya;

5. Mengembangkan pemikiran kewirausahaan, membangun jaringan sosial, sharing dan up-date pengetahuan dan keterampilan untuk mendapatkan akses ke sumber daya. 


\section{Wirausaha Mandiri}

Keinginan/motivasi/komitmen berwirausaha menjadi penting untuk proses munculnya sebuah organisasi bisnis, keinginan/ motivasi/ komitmen menjadi pembentuk pertama dalam serangkaian tindakan untuk mendirikan organisasi, keinginan/ motivasi/ komitmen menjadi indikator yang kuat dari perilaku yang terkendali/terarah. Pada umumnya, niat kewirausahaan adalah produk dari kombinasi pemikiran rasional dan intuitif, faktor ekonomi, kepribadian dan kemampuan personal untuk menciptakan usaha, yang ada akhirnya mengarahkan perilaku. Dalam kewirausahaan faktor penting lainnya adalah kelayakan personal (self-efficacy) sebagai perantara yang lebih dominan antara pikiran menciptakan usaha dan niat kewirausahaan (Doan Winkel, Jeff Vanevenhoven, and Kyle Ehrhardt, 2011).

Dalam teori kewirausahaan, penciptaan usaha merupakan hasil dari strategi pembelajaran kontekstual dalam mengikat materi kewirausahaan dengan situasi dunia nyata, dan mendorong siswa dapat membuat koneksitas pengetahuan yang dimiliki dengan kehidupan sehari-hari (Parvaneh Gelard and Korosh Emami Saleh, 2011). Sikap dan persepsi dasar (atitude, perceived desirability dan perseived feasibility) dalam kaitannya dengan niat menciptakan usaha. Niat menjadi elemen dasar dalam menjelaskan perilaku, menunjukkan upaya orang untuk melakukan sesuatu, ia menjadi faktor yang mempengaruhi perilaku. Implikasinya, bahwa niat (yang baik) berlaku pada semua bentuk tindakan (yang baik) akan memberikan hasil yang baik dalam bidang yang beragam, termasuk pilihan karir profesional, hubungan niat memulai dan melaksanakan serta kinerja yang lebih efektif. Kajian empiris menunjukkan bahwa niat merupakan prediktor akurat bagi perilaku (terencana), niat menjelaskan tidak kurang dari 30\% dari varians perilaku, perilaku yang direncanakan dapat berubah sesuai tuntutan perkembangan, waktu dan situasi ketika individu berinteraksi dengan lingkungan (Ishfaq Ahmed, et al, 2010 )

\section{Hasil Riset Terdahulu}

Kewirausahaan di suatu wilayah atau negara dengan laju pertumbuhan ekonomi, tidak ada negara yang memiliki tingkat kewirausahaannya rendah, pertumbuhan ekonominya tinggi. Edward dan Charles (2011) meneliti 5.500 wirausaha di 36 negara menunjukkan bahwa pertumbuhan ekonomi dipengaruhi oleh aktivitas kewirausahaan. Wirausahawan mampu menempatkan sebuah bangsa menjadi lebih sejahtera, menghasilkan penjualan tahunan lebih dari \$ 200.000.000.000, mewakili lebih dari 26 $\%$ penjulan perusahaan besar negara yang bersangkutan, mampu menciptakan 269.250 pekerjaan/pertahun untuk ekonomi nasional.

\section{METODE PENELITIAN}

Bahwa pembelajaran kewirausahaan yang dirancang dengan model CBE2L yang berfokus proses pembelajaran pengalaman, eksploitasi, eksperimentasi dan pengembangan keterampilan yang penting untuk start-up bisnis dalam sektor yang disukai oleh siswa dapat menghasilkan pemikiran inovatif, kreatif dan opsi solusi untuk bisnis yang ditekuni oleh para siswa .

Lokasi penelitian ini dilaksanakan di SMK Negeri Yogyakarta yang memiliki bidang keahlian Bisnis dan Manajemen (guru dan murid). Peubah/variable yang diukur dalam penelitian ini adalah Implementasi Model Pembelajaran Kewirausahaan Berbasis Kompetensi dan Pengalaman Untuk Menciptakan Wirausaha Baru Pada Siswa SMK Yogyakarta, yang dipilah menjadi variable-variabel dalam gambar 3 .

Untuk kepentingan analisis statistik, data diukur berdasarkan skala likert yang disederhanakan menjadi 4 (empat) pilihan jawaban.. Populasi dan Sampel Penelitian adalah para siswa dan para guru 


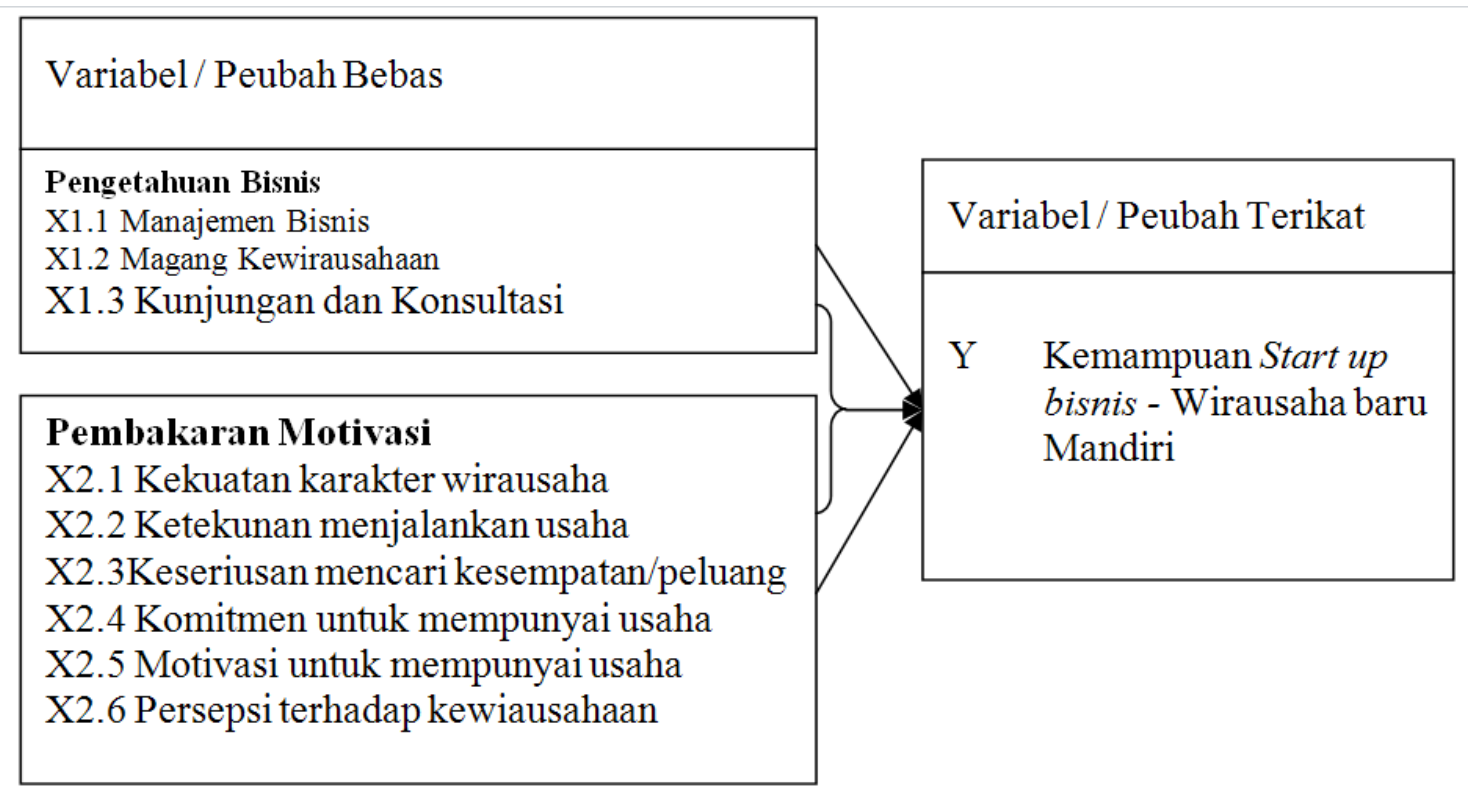

Gambar 3 Paradigma Penelitian

kewirausahaan SMK di Yogyakarta terdiri dari siswa kelas IX, X dan XI, bidang keahlian bisnis dan manajemen serta kelompok tim pengajar (guru) kewirausahaan. Metode pengambilan sampel penelitian ini digunakan metode cluster samplingdalam jumlah sampel minimal terpenuhi (quota sampling). Besarnya ukuran sampel (sample size) sebagai unit analisis yang diambil dari populasi sebesar \pm 480 siswa cukup diambil 214 (Uma Sekaran. 2006), dan untuk mengantisipasi non-return serta incomplete responds disediakan cadangan 5\% sehingga total sampel mencapai 240 .

Design penelitian ini termasuk dalam kategori metode survey menggunakan kuesioner sebagai instrumen utama untuk mengumpulkan data. Alat ukur yang digunakan untuk mendapatkan data itu valid. Valid berarti instrumen tersebut dapat digunakan untuk mengukur apa yang seharusnya diukur. Mampu mengungkap dengan jitu apa yang akan diungkap, menjaring ikan-ikan yang akan dijaring, dan mengukur apa yang akan diukur.Validitas (kesahihan) kuesioner secara teoritis dirancang berdasarkan Construct Validity yang dihitung berdasarkan part whole estimated . uji Keandalan (reliabilitas), digunakan beberapa kali untuk mengukur obyek yang sama akan meng-hasilkan data yang sama. Peratangung-jawaban reliabilitasnya digunakan Cronbach Alpha

Anailis data dalam penelitan ini menggunakan regresi linear berganda, merupakan hubungan yang lebih dari dua variable.Artinya tidak bahwa tidak ada nilai $\mathrm{Y}$ tertentu untu $\mathrm{X}$ dan terdapat banyak kemungkinan nilai $\mathrm{Y}$ untuk niai $\mathrm{X}$ karena nilai Y dipengaruhi banyak variable. Analisi ini digunakan karena skala yang digunakan pada penelitian ini merupakan interval termasuk ke dalam statistik parameter. Maka alat uji yang paling tepat untuk menguji variable Independen $(\mathrm{X})$ dengan variable dependen (Y) adalah menggunakan regresi linear berganda.

\section{HASIL PENELITIAN DAN PEMBAHASAN}

\section{Analisis Regresi Linear Berganda}

Penelitian ini menggunakan analisis model regresi linear berganda karena variabel $\mathrm{X}$ lebih dari satu dalam mempengaruhi variabel Y. Berdasarkan hasil analisis, persamaan regresi yang didapat adalah 
sebagai berikut:

$\mathrm{Y}=0,163+0,070 \mathrm{X}_{1}+0,287 \mathrm{X}_{2}$

1. Besarnya nilai konstanta dari model tersebut sebesar 0,163. Nilai ini berarti bila diasumsikan tidak ada Pengetahuan Bisnis, maka skor Pembakaran Motivasi sebesar 0,163 .

2. Nilai $0,070 X_{1}$ dari model tersebut yang menunjukkan bahwa setiap adanya penambahan sebesar satu satuan dalam variabel Pengetahuan Bisnis, maka akan ada kenaikan nilai pada variabel Pembakaran Motivasi sebesar 0,070 dengan asumsi variabel bebas lain konstan.

3. Nilai $0,287 \mathrm{X}_{2}$ dari model tersebut yang menunjukkan bahwa setiap adanya penambahan sebesar satu satuan dalam pengetahuan binis, maka akan ada kenaikan nilai pada variabel Pembakaran Motivasi sebesar 0,287 dengan asumsi variabel bebas lain konstan

Tabel 3 Analisis Regresi

\begin{tabular}{|c|c|c|c|c|c|c|}
\hline \multirow{2}{*}{\multicolumn{2}{|c|}{ Model }} & \multicolumn{2}{|c|}{ Unstandardized Coefficients } & \multirow{3}{*}{$\begin{array}{c}\begin{array}{c}\text { Standardized } \\
\text { Coefficients }\end{array} \\
\text { Beta }\end{array}$} & \multirow[t]{2}{*}{$\mathrm{t}$} & \multirow{2}{*}{ Sig. } \\
\hline & & B & Std. Error & & & \\
\hline \multirow[t]{3}{*}{1} & (Constant) & 0.163 & 0.985 & & 0.165 & 0.869 \\
\hline & Pengetahuan Bisnis & 0.070 & 0.056 & 0.089 & 1.253 & 0.212 \\
\hline & Pembakaran Motivasi & 0.287 & 0.031 & 0.659 & 9.313 & 0.000 \\
\hline \multicolumn{7}{|c|}{$F=92.900 \quad$ Sign $=.000^{a}$} \\
\hline \multicolumn{7}{|c|}{ Adjusted R Square $=.514$} \\
\hline
\end{tabular}

\section{Uji F (Uji Simultan)}

Dari hasil Output SPSS diketahui nilai $F_{\text {hitung }}$ sebesar 92,900 dan berdasarkan tabel $\mathrm{F}$ diketahui nilai $\mathrm{F}_{\text {tabel }}$ sebesar 3, $073 \quad(\mathrm{df}=2: 110)$. Oleh karena nilai $\mathrm{F}_{\text {hitung }}$ $>\mathrm{F}_{\text {tabel }}(92,900>3,073)$ dan $\mathrm{p}<0,05$, maka dapat disimpulkan bahwa model regresi tersebut dapat dipakai untuk memprediksi variabel Kemampuan Wirausaha. Artinya, secara bersama-sama Pembakaran Motivasi dan Pengetahuan Bisnis mempengaruhi Kemampuan Wirausaha

Berdasarkan perbandingan nilai $\mathrm{F}_{\text {hitung }}>\mathrm{F}_{\text {tabel, }}$ maka hipotesis penelitian $\mathrm{H}_{a}$ yang menyatakan bahwa ada pengaruh Kemampuan Wirausaha. Artinya, secara bersama-sama Pembakaran Motivasi dan Pengetahuan Bisnis mempengaruhi Kemampuan Wirausaha

Nilai koefisien $\mathrm{R}$ square diketahui sebesar 0,519, artinya lingkungan Pemabakaran Motivasi dan Pengethauan Bisnis sebesar 51.9\%. Sedangkan sisanya sebesar $48,1 \%$ dipengaruhi atau dijelaskan oleh variable-variabel lain yang tidak diteliti dalam penelitian ini.

\section{KESIMPULAN, IMPLIKASI DAN SARAN}

\section{Kesimpulan}

1. Tidak ada pengaruh dari variabel Pengetahuan Bisnis terhadap Kemampuan Wirausaha Pengaruh $\mathrm{X}_{1}$ (Pengetahuan Bisnis) terhadap $\mathrm{Y}$ (Kemampuan Wirausaha). Nilai $t_{\text {hitung }}$ variabel $\mathrm{X}_{1}$ diketahui sebesar 1.253 dan signifikansi sebesar 0,212. Berdasarkan tabel $\mathrm{t}$ diketahui nilai $\mathrm{t}_{\text {tabel }}$ dengan $\mathrm{dk}=\mathrm{n}-1$ $(175-1=174)$ dan taraf kesalahan $\alpha=5 \%$, sebesar1,660. Oleh karena nilai $t_{\text {hitung }}>t_{\text {tabel }}$ $(1,253<1,660)$ dan nilai $\mathrm{p}<0,05$,

2. Pengaruh $\mathrm{X}_{2}$ (Pembakaran Motivasi) terhadap Y (Kemampuan Wirausaha). Nilai $t_{\text {hitung }}$ variabel $X_{2}$ diketahui sebesar 9,313 dan signifikansi sebesar 0,000. Berdasarkan tabel $\mathrm{t}$ diketahui nilai $\mathrm{t}_{\text {tabel }}$ dengan $\mathrm{dk}=\mathrm{n}-1(175-1=174)$ dan taraf 
kesalahan $\alpha=5 \%$, sebesar 1,660. Oleh karena nilai $\mathrm{t}_{\text {hitung }}>\mathrm{t}_{\text {tabel }}(9,313>1,660)$ dan nilai $p<0,05$, maka dapat disimpulkan bahwa terdapat pengaruh dari variabel Pembakaran Motivasi terhadap Kemampuan Wirausaha .

3. Dari hasil Output SPSS diketahui nilai $\mathrm{F}_{\text {hitung }}$ sebesar 92,900 dan berdasarkan tabel $\mathrm{F}$ diketahui nilai $\mathrm{F}_{\text {tabel }}$ sebesar 3, 073 $(\mathrm{df}=2: 110)$. Oleh karena nilai $\mathrm{F}_{\text {hitung }}>\mathrm{F}_{\text {tabel }}$ $(92,900>3,073)$ dan $p<0,05$, maka dapat disimpulkan bahwa model regresi tersebut dapat dipakai untuk memprediksi variabel Kemampuan Wirausaha . Artinya, secara bersama-sama Pembakaran Motivasi dan Pengetahuan Bisnis mempengaruhi Kemampuan Wirausaha

\section{Implikasi}

Pembakaran motivasi bagi siswa di SMKN 4,6,7 di Kota Madya Yogyakarta sangat diperlukan bagi siswa guna mencapaia Kemampuan berwirausaha.Melalui mata pelajaran Kewirausaahan dan juga Guru Konseling sangat mempunyai peranan tinggi guna mencapai tujuan sebagai wira usaha mandiri.

\section{Saran}

Kewirausahaan adalah suatu niatan dan keberanian dalam pola pegambilan keputusan,pada siswa yang berumur antara 14 - 19 tahun dimana siswa pada masa umur pencarian jati diri. Siswa yang mengambil Jurusan Sekolah Menengah Kejuruan yang kebanyakan wanita diharapkan oleh orang tuanya setelah lulus untuk bekerja atau membuat usaha sendiri.Dikarenakan beberapa faktor salah satunya adalah kemampuan orang tua siswa sebagai karyawan swasta dengan kemampuan keuangan terbatas.Pembakaran Motivasi melaui pendampingan secara aktif merupakan salah satu cara siswa untuk mencapai tujuannya .

\section{DAFTAR PUSTAKA}

Ali Hasan, dan Budi. Hermawan, 2014. Civilizing Entrepreneurship in The University. International Journal of Management Studies. Vol 1, No.1. pp 4-15

Anderson, A. and Jack, S. 2008. Role typologies for enterprising education professional. Journal of Small Business and Enterprise Development, 15 (2), pp 259-273.

Belousova, O, Gailly, B, Basso, O. 2010. An integrative model of corporate entrepreneurial behavior. Journal Research of Entrepreneurship and Small Business. Vol. 09, No. 16, pp $1-31$

Cope, J. 2005. Towards a dynamic learning perspective of entrepreneurship. Journal Entrepreneurship Theory and Practice, Vol. 29 (4), pp 373397.

Doan Winkel, Jeff Vanevenhoven, and Kyle Ehrhardt, 2011. An Integration and Extension of Dominant Based Models Social Cognitive Career Theory.Entrepreneurial Intentions Research. pp 1164-85

Edward, B. and Charles E. 2011. Entrepreneurial Impact. Journal of Economic Trends and Entrepreneurship. Vol. 7, Issue 2 (1), pp 31-49.

Gibb, A. 2002.In pursuit of a new 'enterprise' and 'entrepreneurship' paradigm for learning: creative destruction, new values, new ways of doing things and new combinations of knowledge. International Journal of Management Reviews, Vol.1. 4(3), pp 233-269.

Fadzean, E., O'Loughlin, A., Shaw, E. 2005. Corporate entrepreneurship and innovation part 1: the missing link. 
Journal of Innovation Management, Vol. 8 (3), pp 350-372.

Hannon, M., Leitch, C. and Hazlett, A. 2006. Measuring the impact of entrepreneurship education: a cognitive approach to evaluation. International Journal of Continuing Engineering Education and Life Long Learning, Vol. 16 (5), pp 400419.

Isaac, S. and Michael, W.B. 1995. Handbook in Research and Evaluation; For Education and BehavioralSciences. $3^{\text {rd }}$ ed. San Diego, CA: Edits Publisher.

Ishfaq Ahmed, Muhammad Musarrat Nawaz,
Zafar Ahmad, Muhammad Zeeshan Shaukat, Ahmad Usman, Wasimul-Rehman and Naveed Ahmed, 2010. Determinants of Students' Entrepreneurial Career Intentions. European Journal of Social Sciences. Volume 15, Number 2, pp 14-22

Marvel, M.R. and Lumpkin, G.T. 2007. Technology entrepreneurs' human capital and its effects on innovation radicalness. Journal of Entrepreneurship Theory and Practice, Vol. 31(6), pp 807-827.

Minniti, M., and Bygrave, W. 2001.A dynamic model of entrepreneurial learning. Journal of Entrepreneurship Theory and Practice, Vol 25(3), 5-16 